\title{
Assessing the activity coefficients of water in cholinium-based ionic liquids: Experimental measurements and COSMO-RS modeling
}

\author{
Imran Khan a , Kiki A. Kurnia a , Tânia E. Sintra a , Jorge A. Saraiva ${ }^{a}$, \\ Simão P. Pinho ${ }^{\mathrm{b}}$, João A.P. Coutinho ${ }^{\mathrm{a}, *}$ \\ a Departamento de Química, CICECO and QOPNA, Universidade de Aveiro, Campus Universitário de Santiago, $3810-193$ Aveiro, Portugal \\ ${ }^{\mathrm{b}}$ LSRE/LCM, Departamento de Tecnologia Química e Biológica, Instituto Politécnico de Bragança, Campus de Santa Apolónia, 5301-857 Bragança, Portugal
}

\section{A R T I C L E I N F O}

\section{Article history:}

Received 28 July 2013

Received in revised form

20 September 2013

Accepted 16 October 2013

Available online 24 October 2013

\section{Keywords:}

Water activity

Choline

COSMO-RS

Ab initio

\begin{abstract}
A B S T R A C T
The vapor liquid-equilibrium of water + ionic liquids is relevant for a wide range of applications of these compounds. It is usually measured by ebulliometric techniques, but these are time consuming and expensive. In this work it is shown that the activity coefficients of water in a series of cholinium-based ionic liquids can be reliably and quickly estimated at $298.15 \mathrm{~K}$ using a humidity meter instrument. The cholinium based ionic liquids were chosen to test this experimental methodology since data for water activities of quaternary ammonium salts are available in the literature allowing the validation of the proposed technique.

The COSMO-RS method provides a reliable description of the data and was also used to understand the molecular interactions occurring on these binary systems. The estimated excess enthalpies indicate that hydrogen bonding between water and ionic liquid anion is the dominant interaction that governs the behavior of water and cholinium-based ionic liquids systems, while the electrostatic-misfit and van der Walls forces have a minor contribution to the total excess enthalpies.

The results here reported show that water activity measurements allow a quick scan for selecting ionic liquids according to their behavior in mixtures with water.
\end{abstract}

(C) 2013 Elsevier B.V. All rights reserved.

\section{Introduction}

Ionic liquids have unique properties such as negligible vapor pressure at room temperature, non-flammability, and their ability to dissolve organic and inorganic compounds, make them attractive for the scientific community and a variety of industrial applications. Chemically, ionic liquids are composed by a bulky organic cation coupled with a disperse charge, and an asymmetric organic or inorganic anion [1]. Limitless combinations of cation and anion that form the ionic liquids lead to different physical properties and phase behavior, thus allowing ionic liquids to be labeled as "designer" solvents. Although most works on this subject deal with imidazolium-based ionic liquids these have several limitations in what concerns their thermal and chemical stability, price, toxicity and biodegradability [2-7]. To overcome these issues, ions derived from natural resources have emerged as completely bio-derived ionic liquids, such as cholinium-based ionic liquids. Cholinium chloride (also known as choline chloride, 2-hydroxyethyltrimethyl ammonium chloride or vitamin B4) is a cheap organic salt with high melting/degradation point $\left(298-304^{\circ} \mathrm{C}\right)$. Early works on the

\footnotetext{
* Corresponding author. Tel.: +351234 401 507; fax: +351234 370084

E-mail address: jcoutinho@ua.pt (J.A.P. Coutinho).
}

use of choline chloride were published in 2001 when Abbot et al. [8] reported for the first time the novel "deep eutectic solvents" composed of $\mathrm{MCl}_{2}(\mathrm{M}=\mathrm{Zn}$ or $\mathrm{Sn})$ with choline chloride in a 2:1 ratio. Since then, these cholinium-based deep eutectic solvents have been studied on many applications, especially as solvent for electrodeposition of metals [9-14].

Recent works have reported the preparation of novel choliniumbased ionic liquids with different anions [15-17]. These choliniumbased ionic liquids show excellent biodegradability [18] and low toxicity $[15,16,19,20]$. Pernak et al. reported the synthesis and characterization of 63 cholinium based ionic liquids [15]. Their results showed that these ionic liquids were active against microbes and manifest excellent antielectrostatic properties. Besides being biocompatible and biodegradable, cholinium-based ionic liquids can also be prepared from cheap natural resources. Not surprisingly, the use of cholinium-based ionic liquids as alternatives to the traditional ionic liquids has attracted the scientific interest for the past few years, with applications as diverse as solvent for absorption of ammonia [21,22] and $\mathrm{CO}_{2}$ [23], isolation of suberin from cork [24], effective solvents for pretreatment of rice straw biomass [25] and lignocellulosic material [26], catalytic reactions [27,28], and extraction of antibiotics using aqueous biphasic systems [29].

Despite their interest, the physical properties of pure choliniumbased ionic liquids $[15,30,31]$ and their mixtures with water or 
other organic solvents are still poorly characterized [32-34]. The thermodynamic and transport properties of ionic liquids and their mixtures with water are crucial to understand the molecular interactions between the components of the mixture and also for designing applications such as absorptive cooling, gas dehydration, extractive distillation, and liquid-liquid extraction, among others. A suitable and widely accepted approach for the description of those interactions is the determination of activity coefficients [35]. They are a fundamental thermodynamic quantity providing a convenient measure of the solution nonideality and component compatibility. Their experimental assessment requires the measurement of phase equilibrium data. There are multiple possible approaches depending on the physical state of the compounds to carry these phase equilibrium measurements. For aqueous systems with a non volatile liquid compound the measurement of vapour liquid equilibrium is the most used, but in aqueous systems containing ionic liquids it is expensive and time consuming. Not only the available equipments, developed for conventional solvents, require a large sample volume ranging from the $250 \mathrm{~cm}^{3}$ of Wang et al. [36] down to the recently reported used of a glass Fischer Labodest equilibrium still that requires a sample volume of circa $35 \mathrm{~cm}^{3}$ [37-43]. Moreover the high viscosity of the mixtures rich in ionic liquid difficult a regular boiling of the mixture, what causes long equilibration times, easily reaching $6 \mathrm{~h}$. To overcome these limitations we have recently reported a microebulliometer of just $8 \mathrm{~cm}^{3}$ of capacity to study these systems [44]. The ebulliometer measurements remain, however, a difficult and very time consuming task so with aim at developing an experimental technique that would provide a fast, reliable and cheap scan of ionic liquids, and their interaction with water, the measurement of water activities using a hygrometer is proposed. This is a fast and reliable technique to assess the activity coefficients of water in systems with non volatile solutes $[45,46]$, and it is here used, for the first time, for measurements of ionic liquid systems. The availability of water activity data for some quaternarium ammonium salts [47] that allows the validation of the technique for similar compounds was one of the reasons to study the cholinium-based ionic liquids.

This work is aimed at proposing a new experimental technique for studying the molecular interactions of water and choliniumbased ionic liquids. For this purpose, it is initially shown that the method here adopted for the measurement of water activities is reliable for aqueous solutions of quaternary ammonium salts and cholinium chloride, for which previously data in the literature are available from isopiestic measurements. The water activities in nine aqueous solutions of cholinium-based ionic liquids are then measured and the water activity coefficients calculated from these values. In addition, COSMO-RS, a quantum chemical-based thermodynamic prediction model, was used to investigate the molecular interactions of water and ionic liquids. The advantage of COSMORS $[48,49]$, compared to the widely used Non-Random Two Liquid (NRTL) thermodynamic model used $[50,51]$ is that not only it can predict the activity coefficients of water in ionic liquids, but it also can provide the sigma profile and potential of pure compounds, and predictions of thermodynamic properties such as excess enthalpy and entropies. The $\sigma$-profile can be used to understand the behavior of the molecule in terms of their polarity, while the $\sigma$-potential describes the likeliness of the molecules studied to interact with other molecules that have a charge density $[p x(\sigma)]$ and polarity $\sigma[48,49]$. Whereas the excess properties can be used to understand the interaction between ionic liquid and water in the mixture state. The COSMO-RS model has been successfully used in the past to estimate the thermodynamic properties of systems containing ionic liquids, including liquid-liquid equilibrium and activity coefficients of its mixture with water or organic solutes [52-59]. After evaluating the capacity of the COSMO-RS model to describe the experimental activity coefficients, this is used to analyze and discuss the molecular interactions that affect the mixing properties of the cholinium-ionic liquids and water, which are also supported by $a b$ initio calculations [60-63].

\section{Experimental}

\subsection{Materials}

Cholinium chloride, $[\mathrm{Ch}] \mathrm{Cl}$; cholinium dihydrogencitrate, [Ch]DHCit; cholinium bicarbonate, [Ch]Bic; and cholinium bitartrate, [Ch]Bit, were acquired from Sigma Aldrich. Cholinium acetate, [Ch]Ac; cholinium dihydrogenphosphate, [Ch]DHph and cholinium salicylate, [Ch]Sal were obtained from Iolitec and cholinium glycolate, [Ch]Gly and cholinium lactate [Ch]Lac were synthesized in our lab according to well established procedures $[15,64]$. Fig. 1 depicts the chemical structures of the studied cholinium-based ionic liquids. To remove traces of water and volatile compounds, individual samples of each ionic liquid were dried at moderate temperature $(\approx 323 \mathrm{~K})$ and at high vacuum $\left(\approx 10^{-5} \mathrm{~Pa}\right)$, under constant stirring, and for a minimum period of $48 \mathrm{~h}$. After this purification, the purity of all ionic liquid samples was further checked by ${ }^{1} \mathrm{H}$, and ${ }^{13} \mathrm{C}$ NMR, and shown to be $\geq 98 \mathrm{wt} \%$. The water content of each ionic liquid was determined by Karl Fischer titration (Mettler Toledo DL32 Karl Fischer coulometer using the Hydranal-Coulomat E from Riedel-de Haen as analyte) and found to be less than $30 \times 10^{-6}$ mass fraction. Double distilled water, passed through a reverse osmosis system and further treated with a Milli-Q plus 185 water purification equipment, was used in all experiments.

\subsection{Measurement of water activities}

The measurements of water activities $\left(a_{w}\right)$ were performed using a Novasina hygrometer LabMaster- $\mathrm{a}_{\mathrm{w}}$ (Lucerne, Switzerland). The measuring principle of the instrument is based on resistiveelectrolytic method. The accuracy of the instrument is $0.001 a_{\mathrm{w}}$, enabling measurements under controlled chamber temperature conditions $( \pm 0.20 \mathrm{~K})$, and was initially calibrated with six saturated pure salt standard solutions (water activity ranging from 0.113 to 0.973), which were included in the instrument. However, to achieve the given accuracy a calibration curve was built using at least six aqueous solutions of $\mathrm{KCl}$ or $\mathrm{CaCl}_{2}$ at different salt molalities. These were chosen based on the expected values for the water activity to be measured in the aqueous solutions containing the ionic liquids. After, the measured values were compared to those recommended in the extensive reviews by Archer [65] for $\mathrm{KCl}$, or Rard and Clegg [66] for $\mathrm{CaCl}_{2}$. For each measurement, samples of approximately $2-3 \mathrm{~cm}^{3}$ prepared in the entire solubility range of the ILs, were charged in proper dishes and placed in the air-tight equilibrium chamber. The exchange of free water takes place until the partial pressure of water vapor reaches the equilibrium, which is confirmed following the $a_{\mathrm{w}}$ variation with time. When a constant value is reached, the water activity is recorded. Diluted solutions reach equilibrium in less than $1 \mathrm{~h}$, but solutions with high concentration of ionic liquids could take up to $8 \mathrm{~h}$.

\subsubsection{Computational details}

The standard procedure for COSMO-RS calculations consists of two steps. First, the continuum solvation COSMO calculations of electronic density and molecular geometry were performed with the TURBOMOLE6.1 program package on the density functional theory level, utilizing the BP functional B88-P86 with a triple- $\zeta$ valence polarized basis set (TZVP) and the resolution of identity standard (RI) approximation [67]. Second, the activity coefficient of water in ionic liquid was calculated using COSMOthermX_2.1 program using the parameter file BP_TZVP_C21_0111 (COSMOlogic 
<smiles>C[N+](C)(C)CCO</smiles>

(i)<smiles>C[N+](C)(C)CCO</smiles>

(iv)<smiles>C[N+](C)(C)CCOC(=O)CC(O)(CC(=O)O)C(=O)O</smiles>

(vii)<smiles>CC(=O)[O-]</smiles>

(ii)

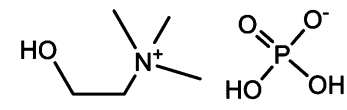

(v)

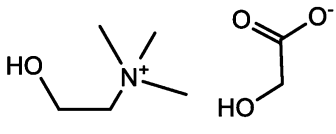

(viii)<smiles>C[N+](C)(C)CCO</smiles>

(iii)<smiles>C[N+](C)(C)CCO</smiles>

(vi)

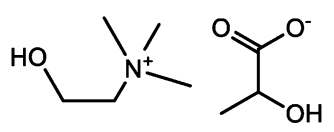

(ix)

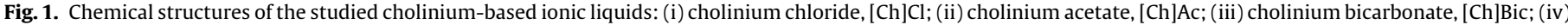

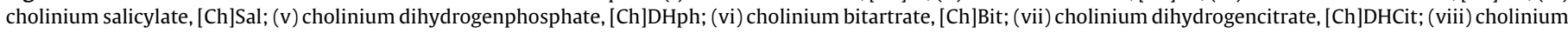
glycolate, [Ch]Gly and (ix) cholinium lactate, [Ch]Lac.

GmbH \& Co KG, Leverkusen, Germany) [68]. The details of the calculation and procedure of estimating activity coefficient using COSMO-RS can be found elsewhere [54]. The $a b$ initio calculations were also performed using TURBOMOLE6.1 with the same parameters described above. It should be noted that the $a b$ initio calculations were done by other authors using a similar approach and no packing effects within the liquids were assumed [62].

\section{Results and discussion}

\subsection{Experimental results}

A validation of the water activity measurement technique here used, on systems similar to those under study, was carried by the measurement of water activities of six tetraalkylammonium halides [47] and [Ch]Cl [69,70], previously reported in literature. A good agreement between the experimental values measured in this work and the literature values was obtained as shown in Figs. $\mathrm{S} 1-\mathrm{S} 3$ in the Supporting Information.

The water activity coefficient $\left(\gamma_{w}\right)$ can be calculated from the water activities as

$\gamma_{w}=\frac{a_{w}}{x_{w}}$

where $a_{w}$ is the water activity, and $x_{w}$ is the mole fraction of water.

Table 1 presents the experimental results for the water activities and activity coefficients of water in the studied cholinium-based ionic liquids in the region of complete miscibility. Excepting $[\mathrm{Ch}] \mathrm{Cl}$, to the best of our knowledge no data on activity coefficient of water in all other studied cholinium-based ionic liquids was previously reported in the literature. All systems studied present water activity coefficients lower than 1 , indicating favorable interactions between water and cholinium-based ionic liquids as depicted in Figs. 2 and 3 (detailed results are presented in Figs. S4-S12). It is remarkable to see that these systems present different trends in the water activities and activity coefficients with the ionic liquid concentration, e.g. significant effect of concentration on the activity coefficient was observed for $[\mathrm{Ch}] \mathrm{Ac}$, meanwhile $[\mathrm{Ch}] \mathrm{Bic}$ and $[\mathrm{Ch}] \mathrm{Cl}$ presented an almost linear dependency. The water activity coefficients follow the trend $[\mathrm{Ch}] \mathrm{Ac}<[\mathrm{Ch}] \mathrm{Lac} \approx[\mathrm{Ch}] \mathrm{Gly}<[\mathrm{Ch}] \mathrm{DHph} \approx[\mathrm{Ch}] \mathrm{Bit} \approx[\mathrm{Ch}] \mathrm{Cl}$ $<$ [Ch]DHCit $<[\mathrm{Ch}] \mathrm{Bic}<[\mathrm{Ch}] \mathrm{Sal}$. These results show that water presented the strongest interaction with [Ch]Ac as can be observed from its lowest activity coefficient. On the other hand, [Ch]Sal has the weaker interaction with water.

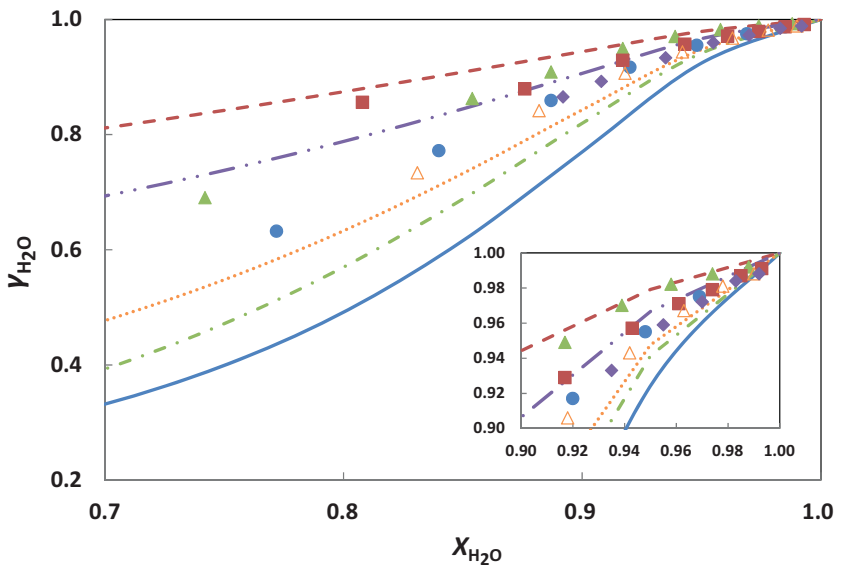

Fig. 2. Experimental activity coefficients of water, $\gamma \mathrm{H}_{2} \mathrm{O}$, as function of the concentration of water at $298.2 \mathrm{~K}$ for [Ch]DHCit ( $\square$, long dashed line), [Ch]Bit ( $\downarrow$, dashed and two dotted line), $[\mathrm{Ch}] \mathrm{Cl}(\bigcirc$, line $),[\mathrm{Ch}] \mathrm{DHph}(\triangle$, dotted line), and $[\mathrm{Ch}] \mathrm{Bic}(\triangle$ dashed-dotted line). The symbols and lines represent the experimental and COSMORS predictions, respectively. (For interpretation of the references to colour in this figure legend, the reader is referred to the web version of this article.)

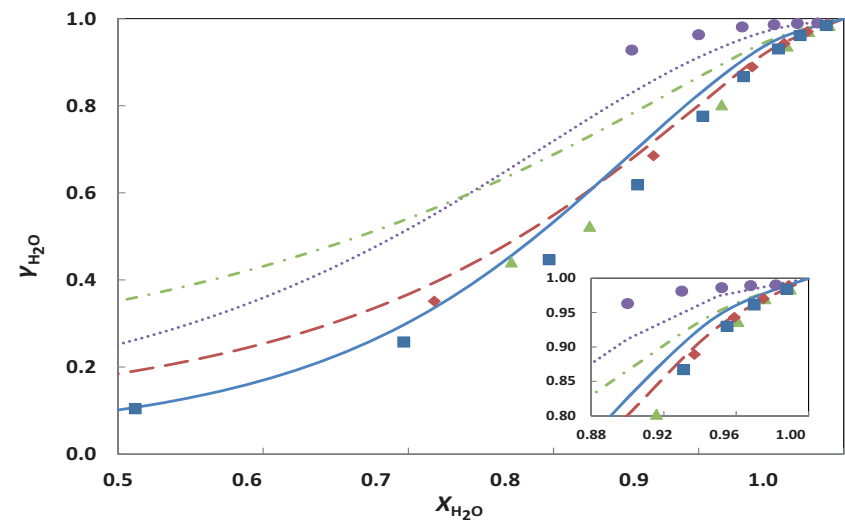

Fig. 3. Effect of structural variation of cholinium-based ionic liquids with carboxylate anions on water activity coefficient, $[\mathrm{Ch}] \mathrm{Ac}(\square$, full line), [Ch] Gly $(\diamond$, long dashed line), $[\mathrm{Ch}] \operatorname{Lac}(\Delta$, dashed-dotted line), and $[\mathrm{Ch}] \mathrm{Sal}(\boldsymbol{}$, dotted line). The symbols and lines represent the experimental and COSMO-RS predictions, respectively. (For interpretation of the references to colour in this figure legend, the reader is referred to the web version of this article.) 
Table 1

Experimental values of water activity $\left(a_{w}\right)$ and activity coefficient of water $\left(\gamma_{w}\right)$ in cholinium-based ionic liquids at $298.2 \mathrm{~K}$.

\begin{tabular}{|c|c|c|c|c|c|c|c|c|}
\hline \multicolumn{3}{|c|}{$\mathrm{H}_{2} \mathrm{O}+[\mathrm{Ch}] \mathrm{Cl}$} & \multicolumn{3}{|c|}{$\mathrm{H}_{2} \mathrm{O}+[\mathrm{Ch}] \mathrm{Ac}$} & \multicolumn{3}{|c|}{$\mathrm{H}_{2} \mathrm{O}+[\mathrm{Ch}] \mathrm{Bic}$} \\
\hline$x_{\mathrm{w}}$ & $a_{\mathrm{w}}$ & $\gamma_{\mathrm{w}}$ & $x_{\mathrm{w}}$ & $a_{\mathrm{w}}$ & $\gamma_{w}$ & $x_{\mathrm{w}}$ & $a_{\mathrm{w}}$ & $\gamma_{w}$ \\
\hline 0.985 & 0.972 & 0.987 & 0.988 & 0.972 & 0.984 & 0.988 & 0.980 & 0.992 \\
\hline 0.969 & 0.944 & 0.975 & 0.970 & 0.933 & 0.961 & 0.974 & 0.962 & 0.988 \\
\hline 0.948 & 0.906 & 0.955 & 0.955 & 0.888 & 0.930 & 0.958 & 0.941 & 0.982 \\
\hline 0.920 & 0.844 & 0.917 & 0.931 & 0.808 & 0.867 & 0.939 & 0.910 & 0.970 \\
\hline 0.887 & 0.762 & 0.859 & 0.903 & 0.701 & 0.776 & 0.917 & 0.870 & 0.949 \\
\hline 0.840 & 0.648 & 0.772 & 0.858 & 0.530 & 0.618 & 0.887 & 0.805 & 0.908 \\
\hline 0.772 & 0.488 & 0.632 & 0.797 & 0.356 & 0.446 & 0.854 & 0.736 & 0.862 \\
\hline \multirow[t]{2}{*}{0.668} & 0.299 & 0.448 & 0.697 & 0.179 & 0.257 & 0.742 & 0.512 & 0.690 \\
\hline & & & & & & 0.647 & 0.369 & 0.570 \\
\hline \multicolumn{3}{|c|}{$\mathrm{H}_{2} \mathrm{O}+[\mathrm{Ch}]$ Sal } & \multicolumn{3}{|c|}{$\mathrm{H}_{2} \mathrm{O}+[\mathrm{Ch}] \mathrm{DHph}$} & \multicolumn{3}{|c|}{$\mathrm{H}_{2} \mathrm{O}+[\mathrm{Ch}] \mathrm{Bit}$} \\
\hline$x_{\mathrm{w}}$ & $a_{\mathrm{w}}$ & $\gamma_{w}$ & $x_{\mathrm{w}}$ & $a_{\mathrm{w}}$ & $\gamma_{w}$ & $x_{\mathrm{w}}$ & $a_{\mathrm{w}}$ & $\gamma_{w}$ \\
\hline 0.982 & 0.972 & 0.990 & 0.990 & 0.978 & 0.988 & 0.992 & 0.980 & 0.988 \\
\hline 0.968 & 0.958 & 0.989 & 0.978 & 0.959 & 0.981 & 0.983 & 0.967 & 0.984 \\
\hline 0.952 & 0.939 & 0.986 & 0.963 & 0.931 & 0.967 & 0.970 & 0.943 & 0.972 \\
\hline 0.930 & 0.912 & 0.981 & 0.942 & 0.889 & 0.943 & 0.955 & 0.916 & 0.959 \\
\hline 0.900 & 0.867 & 0.963 & 0.918 & 0.832 & 0.906 & 0.935 & 0.872 & 0.933 \\
\hline \multirow[t]{2}{*}{0.854} & 0.792 & 0.928 & 0.882 & 0.742 & 0.841 & 0.908 & 0.810 & 0.892 \\
\hline & & & 0.831 & 0.609 & 0.733 & 0.892 & 0.771 & 0.865 \\
\hline \multicolumn{3}{|c|}{$\mathrm{H}_{2} \mathrm{O}+[\mathrm{Ch}] \mathrm{DHCit}$} & \multicolumn{3}{|c|}{$\mathrm{H}_{2} \mathrm{O}+[\mathrm{Ch}] \mathrm{Gly}$} & \multicolumn{3}{|c|}{$\mathrm{H}_{2} \mathrm{O}+[\mathrm{Ch}]$ Lac } \\
\hline$x_{\mathrm{w}}$ & $a_{\mathrm{w}}$ & $\gamma_{w}$ & $x_{\mathrm{w}}$ & $a_{\mathrm{w}}$ & $\gamma_{w}$ & $x_{\mathrm{w}}$ & $a_{\mathrm{w}}$ & $\gamma_{w}$ \\
\hline 0.993 & 0.984 & 0.991 & 0.989 & 0.978 & 0.989 & 0.990 & 0.974 & 0.984 \\
\hline 0.985 & 0.972 & 0.987 & 0.975 & 0.946 & 0.970 & 0.976 & 0.947 & 0.970 \\
\hline 0.974 & 0.954 & 0.979 & 0.959 & 0.904 & 0.943 & 0.961 & 0.901 & 0.937 \\
\hline 0.961 & 0.933 & 0.971 & 0.937 & 0.833 & 0.889 & 0.916 & 0.734 & 0.802 \\
\hline 0.943 & 0.902 & 0.957 & 0.869 & 0.595 & 0.685 & 0.825 & 0.431 & 0.523 \\
\hline 0.917 & 0.852 & 0.929 & 0.718 & 0.252 & 0.351 & 0.771 & 0.229 & 0.441 \\
\hline 0.876 & 0.770 & 0.879 & & & & & & \\
\hline 0.808 & 0.692 & 0.856 & & & & & & \\
\hline
\end{tabular}

\subsection{COSMO-RS: description of pure compounds}

Fig. 4 presents the sigma profile and potential for water, [Ch]Ac, and [Ch]Sal. The sigma profile and potential for the remaining cholinium-based ionic liquids studied are given in Figs. S13 and S14 in the Supporting Information. The sigma profile of water presents peaks corresponding to strong $\mathrm{H}$-bond donor at $-1.6 \mathrm{e} \mathrm{nm}^{-2}$ and acceptor at $1.8 \mathrm{enm}^{-2}$. The sigma potential of this compound presents strongly attractive interactions with both $\mathrm{H}$-bond donor and acceptor in the mixture, although it shows a higher capacity as H-bond donor, as depicted on their sigma potential (Fig. 4b). Therefore, it is expected that water will have high attraction to compounds that have $\mathrm{H}$-bond acceptor group. Regarding the studied cholinium-based ionic liquids, the sigma potential also presents attraction to both $\mathrm{H}$-bond donor and $\mathrm{H}$-bond acceptor group in the mixture. The H-bond donor character arises from the hydroxyl group of the cholinium cation that is indicated by a peak with low intensity at $-1.8 \mathrm{e} \mathrm{nm}^{-2}$ on their sigma profile (Fig. 4a). All the studied anions of the cholinium-based ionic liquids present peaks within the electronegative area indicating their capability as hydrogen-bond acceptor. For example peaks, at $2 \mathrm{e} \mathrm{nm}^{-2}$ corresponding to $\mathrm{Ac}^{-}$and $\mathrm{Sal}^{-}$anions, with the former has slightly higher intensity indicating greater ability to act as $\mathrm{H}$-bond acceptor (Fig. 4a). The presence of aromatic ring of $\mathrm{Sal}^{-}$anion is indicated by significant high intensity of peaks at -0.5 and $0.6 \mathrm{e} \mathrm{nm}^{-2}$ within the non-polar region that make [Ch]Sal more hydrophobic than [Ch]Ac. In addition, the hydroxyl group attached to the aromatic ring, which is known as electron withdrawing, cause the $\mathrm{COO}^{-}$of $\mathrm{Sal}^{-}$anion becomes less negative, thus reducing its ability as H-bond acceptor (Fig. 4a). Therefore, with higher hydrophobic character and lesser ability as $\mathrm{H}$-bond acceptor, it is expected that water will have less attractive character to [Ch]Sal than [Ch]Ac. Among the studied
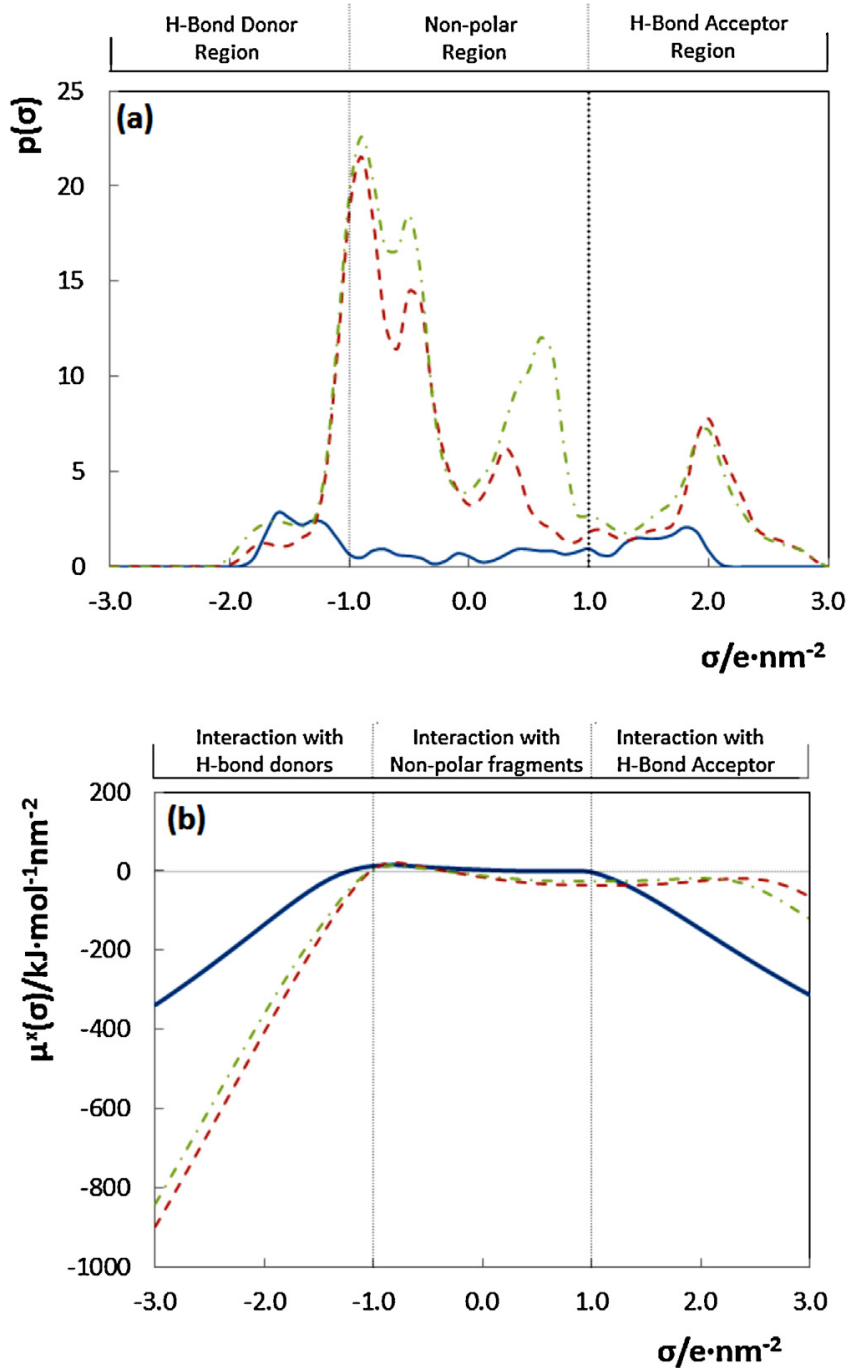

Fig. 4. Sigma profile (a) and potential (b) of $\mathrm{H}_{2} \mathrm{O}$, [Ch][Ac], and [Ch][Sal] (full line, dashed line, dashed-dotted line, respectively).

cholinium-based ionic liquids, [Ch]Ac shows the greatest capacity as $\mathrm{H}$-bond acceptor, which is in agreement to stronger interactions shown by the water activity coefficients measured.

\subsection{COSMO-RS: description of binary mixtures}

The activity coefficient of water in cholinium-based ionic liquids is presented in Fig S4-S12 and the average absolute deviations are reported in Table S1 in the Supporting Information. Figs. 2 and 3 present the comparison between experimental values and COSMO-RS prediction. AAD lesser than $4 \%$ were obtained for the binary mixtures of $\mathrm{H}_{2} \mathrm{O}+[\mathrm{Ch}] \mathrm{Sal}, \mathrm{H}_{2} \mathrm{O}+[\mathrm{Ch}] \mathrm{DHph}$, $\mathrm{H}_{2} \mathrm{O}+[\mathrm{Ch}] \mathrm{Bit}, \mathrm{H}_{2} \mathrm{O}+[\mathrm{Ch}]$ DHCit, and $\mathrm{H}_{2} \mathrm{O}+[\mathrm{Ch}] \mathrm{Gly}$, indicating ability of COSMO-RS to quantitatively predict the activity coefficient of water in the binary mixtures. Even though the binary mixtures $\mathrm{H}_{2} \mathrm{O}+[\mathrm{Ch}] \mathrm{Cl}, \mathrm{H}_{2} \mathrm{O}+[\mathrm{Ch}] \mathrm{Ac}, \mathrm{H}_{2} \mathrm{O}+[\mathrm{Ch}] \mathrm{Bic}$, and $\mathrm{H}_{2} \mathrm{O}+[\mathrm{Ch}]$ Lac have AAD between 10 and 16\%, COSMO-RS still able to qualitatively predict the change of activity coefficient of water in these systems, even if in some cases the relative magnitude of the activity coefficients do not follow the experimental trend. Fig. 3 allows the study of the impact of structural variations of carboxylatebased ionic liquids. The addition of $-\mathrm{OH}$ group to the acetate anion, as in the case of glycolate anion, increases the hydrogen bonding between ionic liquid cation and anion $\left(H_{\mathrm{m}, \mathrm{HB}} / \mathrm{kJ} \mathrm{mol}^{-1}\right.$ 
for $[\mathrm{Ch}][\mathrm{Ac}]=-81.25,[\mathrm{Ch}][\mathrm{Gly}]=-111)$. Thus the water requires more energy to destroy the $\mathrm{H}$-bond between the $[\mathrm{Ch}]^{+}$cation and [Gly] $]^{-}$anion leading to the less interaction of water with [Ch][Gly] observed. The substitution of the $-\mathrm{CH}_{3}$ group of $\mathrm{Ac}^{-}$with an aromatic ring, as in the case of $\mathrm{Sal}^{-}$also significantly reduces their interaction with water, as observed from COSMO-RS predictions as well as experimentally. In this case, the presence of the aromatic ring, as indicated by the big peak at $0.6 \mathrm{enm}^{-2}$ in the non polar region (Fig. 4a), leads to a higher hydrophobic character of the respective ionic liquids, making then thus less attractive to water. Although a superior quantitative agreement was obtained for the activity coefficient of water in [Ch]Ac and [Ch]Gly, deviations were observed for [Ch]Lac and [Ch]Sal. It seems the higher deviations are related to the increase of the hydrophobic character of the ionic liquids. These deviations, also found for $[\mathrm{Ch}] \mathrm{Cl}$ and $[\mathrm{Ch}] \mathrm{Bic}$, might also be caused from the IL-water microstructure formation that it is not taken into account by the COSMO-RS calculations [52,71]. Nevertheless, the results obtained from COSMO-RS calculations show an acceptable agreement with the experimental data, depicting a good predicting capacity of this method. Therefore, the results will be further discussed based on the interactions described by the COSMO-RS model.

COSMO-RS can be applied for a straightforward estimation of interaction energy between ionic liquid and water in the mixture state. The $H_{m}^{E}$ is the change in enthalpy upon mixture of the two components. In the case of water and ionic liquid, it involves the disruption of interaction between water-water and ionic liquid-ionic liquids, and the establishment of interaction in the mixture of water-ionic liquid [59]. In a previous work we have shown the capability of COSMO-RS to predict the excess enthalpies of binary systems composed of water and ionic liquids [59]. In general, COSMO-RS produces a good qualitative agreement with the reported experimental data, and it can thus be used as a priori predictive method. The estimation of $H_{m}^{E}$ in the COSMO-RS method results from summing the specific molecular interactions, namely electrostatic/misfit, $H_{m, M F}^{E}$; hydrogen bonds, $H_{m, H B}^{E}$; and van der Waals forces, $H_{m, V d W}^{E}$. The contribution of each specific molecular interaction to the $H_{m}^{E}$ can be written as,

$H_{m}^{E}=H_{m, M F}^{E}+H_{m, H B}^{E}+H_{m, V d W}^{E}$

Therefore, the COSMO-RS method can be used to analyze the $H_{m}^{E}$ values in terms of specific molecular interaction between components water and cholinium-based ionic liquids.

The estimated $H_{m}^{E}, H_{m, M F}^{E}, H_{m, H B}^{E}$, and $H_{m, V d W}^{E}$ throughout the whole composition for the studied systems are given in Figures S15S22 in the Supporting Information. The estimated excess enthalpies were negative throughout the whole composition, as also observed experimentally for $\left(\mathrm{H}_{2} \mathrm{O}+[\mathrm{Ch}] \mathrm{Gly}\right)$ and $\left(\mathrm{H}_{2} \mathrm{O}+[\mathrm{Ch}] \mathrm{Lac}\right)$ reported by Constantinescu et al. [32]. The reported experimental data, along with its COSMO-RS prediction, are given in Figure S23. It is remarkable to see that minima are present on all systems at $x_{\mathrm{H}_{2} \mathrm{O}} \sim 0.66$ that seem to indicate the formation of a complex between two molecules of water and one molecule of the cholinium-based ionic liquids. Fig. 5 presents the estimated $H_{m}^{E}, H_{m, M F}^{E}, H_{m, H B}^{E}$, and $H_{m, V d W}^{E}$ for water and cholinium-based ionic liquids at $298.2 \mathrm{~K}$ at $x_{\mathrm{H}_{2} \mathrm{O}}=0.66$. The negative $H_{m}^{E}$ value indicates favorable interactions between water and the cholinium-based ionic liquids. For all binary mixtures, the dominant interaction is the hydrogenbonding, which contributes to the exothermicity of the mixtures. These results arise from the rupture of hydrogen bonds among water molecules and the cholinium-based ionic liquids itself, and the establishment of new hydrogen bonds between water and the ionic liquids anion. For example, in the case of water and [Ch]Ac, it can be described as an exothermic mixture due to strong $\mathrm{H}$-bond acceptor of acetate anion, which promotes strong interactions of water and $[\mathrm{Ch}] \mathrm{Ac}$, as can be deduced from the COSMO-RS. The electrostatic interactions are attractive, as indicated by its negative values, which slightly contribute to the total excess enthalpy of the mixture. The van der Waals forces make the smallest contribution to the excess enthalpy values of these mixtures. Therefore, according to the COSMO-RS model, the interaction of water and cholinium-based ionic liquids can be enhanced by proper selection of the anion counterpart.

The excess Gibbs free energy was estimated using COSMO-RS using the following equation

$\frac{G^{\mathrm{E}}}{R T}=\left(x_{w} \cdot \ln \lambda_{w}\right)+\left(x_{I L} \cdot \ln \lambda_{I L}\right)$

where $x$ and $\gamma$ are mole fraction and activity coefficient, respectively, and the subscript $w$ refers to water and $I L$ to the ionic liquid.

The studied mixtures of water and cholinium-based ionic liquids present negative values of excess free Gibbs energy (Figs. S24-S25), which indicates spontaneous dissolution of the ionic liquids into water and vice versa, as observed experimentally. Thus, in this work COSMO-RS proved to be a tool of great value to select and design ionic liquids for a given application, since it gives a rationalization of the selection of the ionic liquids to obtain the type of solvent-solute interaction required.

\subsection{Ab initio calculation}

To gather more information on the possibility of the complex formation between water and cholinium-based ionic liquids

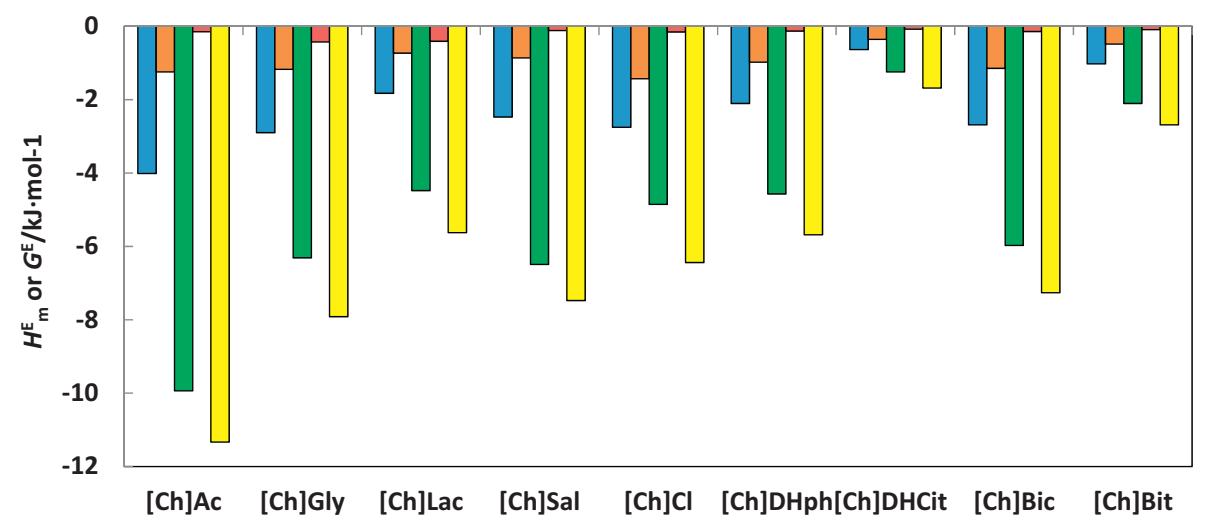

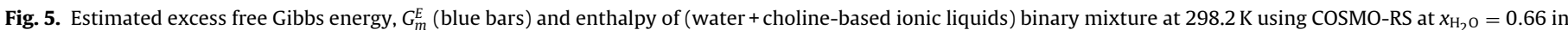

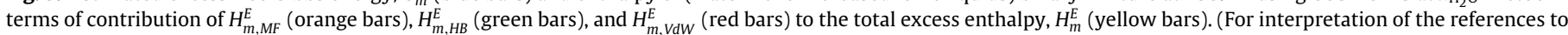
colour in this figure legend, the reader is referred to the web version of this article.) 


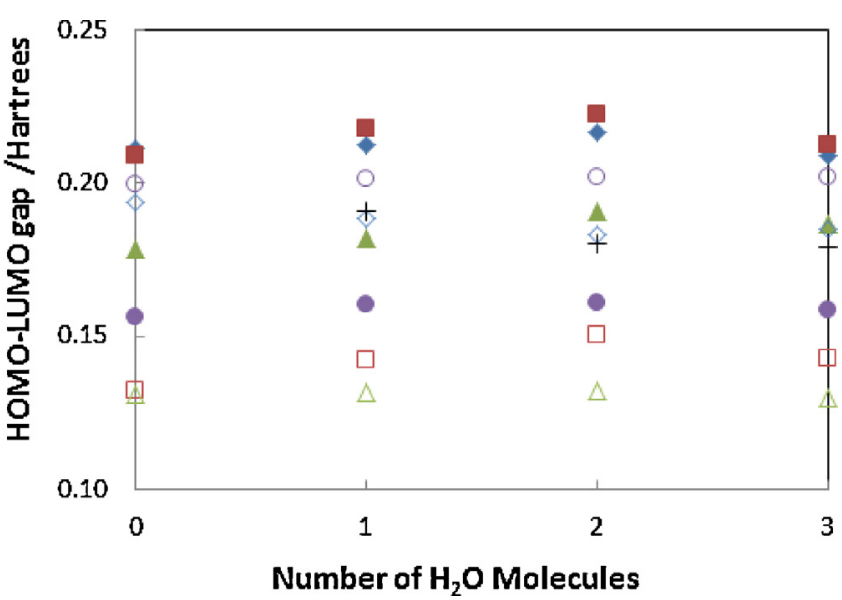

Fig. 6. The HUMO-LUMO gap for the cholinium-based ionic liquids and its complexes with water Symbols: [Ch]Cl $(\checkmark),[\mathrm{Ch}] \mathrm{DHph}(\square),[\mathrm{Ch}] \mathrm{Ac}(\triangle),[\mathrm{Ch}] \mathrm{DHCit}(\mathbf{O})$ $[\mathrm{Ch}] \mathrm{Bic}(\diamond)$, [Ch]Bit $(\square)$, [Ch]Sal $(\triangle)$, [Ch]Gly $(\mathrm{O})$, and $[\mathrm{Ch}] \mathrm{Lac}(+)$. (For interpretation of the references to colour in this figure legend, the reader is referred to the web version of this article.)

discussed above, $a b$ initio calculations were performed. In quantum chemistry methods, there are several basic parameters of importance such as, HOMO (High Occupied Molecular Orbital) energy, LUMO (Low Unoccupied Molecular Orbital) energy, and HOMOLUMO energy gap. Details on the study of the electronic structure principle in static and dynamic situations are given in the reference [62]. The HOMO and LUMO energies are the most important features for the interaction of water and cholinium-based ILs. The interaction is caused by electron flowing from the HOMO, which the highest energy, to the LUMO. Therefore, the higher the HOMO energy, the more reactive the molecule is. On the other hand, LUMO is likely a location for a bond to occur as incoming electrons from other molecules will fill from HOMO into the LUMO orbital. The lower LUMO energy indicates a less stable molecule. The HOMOLUMO energy gap is used as quantum chemical descriptor in establishing correlations for chemical and biochemical systems. A large HOMO-LUMO gap implies high stability for the molecule in the sense of its lower charge transfer in the system. For systems involving water and cholinium-based ionic liquids, the HOMOLUMO gap is more important since it indicates the stability of the complexes formed, as given in Table S2 of Supporting Information for several possible complexes. Water presents the lowest HOMO, highest LUMO, and highest HOMO-LUMO gap energy that translates the high stability of this molecule. On the other hand, the studied cholinium-based ionic liquids present low HOMO-LUMO energy gap. This fact is related with their low LUMO energy, making them more reactive, less stable, and having higher tendency to attract water. The complex $\left\{[\mathrm{Ch}] \mathrm{Ac}-\mathrm{H}_{2} \mathrm{O}\right\}$ has higher HOMO-LUMO gap compared to the pure [Ch]Ac itself, as depicted in Fig. 6, indicating higher stability of the complex molecule. Increasing the number of water molecules to two, also increases the HUMO-LUMO gap. However, the HUMO-LUMO gap decreased for three molecules of water in the cluster. It indicates that two molecules of water and one molecule of [Ch]Ac formed the most stable complex and this finding is in good agreement with the excess enthalpy at minima $x_{\mathrm{H}_{2} \mathrm{O}} \sim 0.66$, in which the ratio of water to ionic liquids is 2 to 1 . The other studied cholinium-based IL also showed maximum HOMO-LUMO gap energy when the ratio of water to ionic liquids is 2 to 1 . The exception was observed for the complex of $\left\{[\mathrm{Ch}]\right.$ Bic $\left.-\boldsymbol{x} \cdot \mathrm{H}_{2} \mathrm{O}\right\}$ and $\left\{[\mathrm{Ch}]\right.$ Lac $\left.-\boldsymbol{x} \cdot \mathrm{H}_{2} \mathrm{O}\right\}$, in which they showed instead minimum HOMO-LUMO gap energy at the same ratio. In any case all the studied systems showed the formation of complexes between two molecules of water and one molecule of ionic liquids. Thus, the $a b$ initio calculations fostered the understanding of the interactions occurring in the binary system of water and cholinium-based ionic liquids in term of molecular orbital level.

\section{Conclusions}

Cholinium-based ionic liquids are regarded as an alternative to the traditional ionic liquids due to their higher biocompatibility, and since they can be obtained from cheaper raw materials. The behavior of cholinium-based ionic liquids with water is very important to design specific applications involving these mixtures. This work proposes a new, fast and reliable experimental technique for the measurement of the activity coefficient of water in ionic liquids by the measurement of water activities. The procedure was validated on the water activities of quaternarium ammonium salts and $[\mathrm{Ch}] \mathrm{Cl}$, and the water activities and activity coefficients in nine cholinium based aqueous systems are reported.

Satisfactory agreement between experimental data and predictions using COSMO-RS was observed. The model shows that the interaction of water in these mixtures is strongly influenced by the type of the anion present in the cholinium-based ionic liquids. Indeed, it was observed $\mathrm{H}$-bond interaction between water, as $\mathrm{H}$-bond donor, with the anion, as $\mathrm{H}$-bond acceptor. The ab initio calculations showed the formation of stable complexes between two molecules of water and one molecule of cholinium-based ILs. The experimental procedure here proposed can be easily applied to other mixtures containing ionic liquids with water to understand the interactions in the mixture.

\section{Acknowledgment}

This work was financed by national funding from Fundação para a Ciência e a Tecnologia (FCT, Portugal), European Union, QREN, FEDER and COMPETE for funding the CICECO (project PestC/CTM/LA0011/2013), QOPNA (project Pest-C/QUI/UI0062/2011) and LSRE/LCM (project Pest-C/EQB/LA0020/2013). Imran Khan and Kiki A. Kurnia acknowledge FCT for the postdoctoral grants SFRH/BPD/76850/2011 and SFRH/BPD/88101/2012, respectively and also Tânia E. Sintra acknowledge FCT doctoral grant SFRH/BD/85871/2012.

\section{Appendix A. Supplementary data}

Supplementary material related to this article can be found, in the online version, at http://dx.doi.org/10.1016/j.fluid.2013.10.032.

\section{References}

[1] P. Wasserscheid, T. Welton (Eds.), Ionic Liquids in Synthesis, 2nd edition, WILEY-VCH Verlag GmbH \& Co. KGaA, Darmstadt, Federal Republic of Germany, 2009.

[2] M. Yu, S.M. Li, X.Y. Li, B.J. Zhang, J.J. Wang, Ecotox. Environ. Safe. 71 (2008) 903-908.

[3] X.Y. Li, J. Zhou, M. Yu, J.J. Wang, Y.C. Pei, Ecotox. Environ. Safe. 72 (2009) $552-556$

[4] R.F.M. Frade, C.A.M. Alonso, Hum. Exp. Toxicol. 29 (2010) 1038-1054.

[5] M. Besnard, M.I. Cabaço, F. Vaca Chávez, N. Pinaud, P.J. Sebastião, J.A.P. Coutinho, J. Mascetti, Y. Danten, J. Phys. Chem. A 116 (2012) 4890-4901.

[6] D. Coleman, N. Gathergood, Chem. Soc. Rev. 39 (2010) 600-637.

[7] A. Romero, A. Santos, J. Tojo, A. Rodríguez, J. Hazard. Mater. 151 (2008) 268-273.

[8] A.P. Abbott, G. Capper, D.L. Davies, H.L. Munro, R.K. Rasheed, V. Tambyrajah, Chem. Commun. (2001) 2010-2011

[9] A.P. Abbott, D. Boothby, G. Capper, D.L. Davies, R.K. Rasheed, J. Am. Chem. Soc 126 (2004) 9142-9147.

[10] A.P. Abbott, G. Capper, K.J. McKenzie, K.S. Ryder, J. Electroanal. Chem. 599 (2007) $288-294$

[11] A. Bakkar, V. Neubert, Electrochem. Commun. 9 (2007) 2428-2435.

[12] A.P. Abbott, K. El Ttaib, K.S. Ryder, E.L. Smith, T I Met Finish 86 (2008) 234-240.

[13] R. Böck, S.E. Wulf, T I Met Finish 87 (2009) 28-32

[14] F. Golgovici, T. Visan, Chalcogenide Lett. 9 (2012) 165-174. 
[15] J. Pernak, A. Syguda, I. Mirska, A. Pernak, J. Nawrot, A. Pradzynska, S.T. Griffin, R.D. Rogers, Chem. Eur. J. 13 (2007) 6817-6827.

[16] P. Nockemann, B. Thijs, K. Driesen, C.R. Janssen, K. Van Hecke, L. Van Meervelt, S. Kossmann, B. Kirchner, K. Binnemans, J. Phys. Chem. B 111 (2007) 5254-5263.

[17] Z. Li, X. Liu, Y. Pei, J. Wang, M. He, Green Chem. 14 (2012) 2941-2950.

[18] M. Petkovic, J.L. Ferguson, H.Q.N. Gunaratne, R. Ferreira, M.C. Leitao, K.R. Seddon, L.P.N. Rebelo, C.S. Pereira, Green Chem. 12 (2010) 643-649.

[19] X. Wang, C.A. Ohlin, Q. Lu, Z. Fei, J. Hu, P.J. Dyson, Green Chem. 9 (2007) $1191-1197$.

[20] S.P.M. Ventura, F.A. Silva, A.M.M. Gonçalves, J.L. Pereira, F. Gonçalves, J.A.P. Coutinho, Ecotox. Environ. Safe. (2013), Submitted.

[21] J. Palomar, M. Gonzalez-Miquel, J. Bedia, F. Rodriguez, J.J. Rodriguez, Sep. Purif. Technol. 82 (2011) 43-52.

[22] J. Bedia, J. Palomar, M. Gonzalez-Miquel, F. Rodriguez, J.J. Rodriguez, Sep. Purif. Technol. 95 (2012) 188-195.

[23] S. Aparicio, M. Atilhan, J. Phys. Chem. B 116 (2012) 9171-9185

[24] R. Ferreira, H. Garcia, A.F. Sousa, M. Petkovic, P. Lamosa, C.S.R. Freire, A.J.D. Silvestre, L.P.N. Rebelo, C.S. Pereira, New J. Chem. 36 (2012) 2014-2024.

[25] X.D. Hou, T.J. Smith, N. Li, M.H. Zong, Biotechnol. Bioeng. 109 (2012) 2484-2493.

[26] K. Ninomiya, A. Ohta, S. Omote, C. Ogino, K. Takahashi, N. Shimizu, Chem. Eng. J. 215 (2012) 811-818.

[27] S. Abello, F. Medina, X. Rodriguez, Y. Cesteros, P. Salagre, J.E. Sueiras, D. Tichit, B. Coq, Chem. Commun. (2004) 1096-1097.

[28] S. Hu, T. Jiang, Z. Zhang, A. Zhu, B. Han, J. Song, Y. Xie, W. Li, Tetrahedron Lett. 48 (2007) 5613-5617.

[29] J.F.B. Pereira, F. Vicente, V.C. Santos-Ebinuma, J.M. Araújo, A. Pessoa, M.G. Freire, J.A.P. Coutinho, Process Biochem. 48 (2013) 716-722.

[30] A.J. Costa, M.R. Soromenho, K. Shimizu, I.M. Marrucho, J.M. Esperanca, J.N. Lopes, L.P. Rebelo, ChemPhysChem 13 (2012) 1902-1909.

[31] N. Muhammad, M.I. Hossain, Z. Man, M. El-Harbawi, M.A. Bustam, Y.A. Noaman, N.B. Mohamed Alitheen, M.K. Ng, G. Hefter, C.Y. Yin, J. Chem. Eng. Data 57 (2012) 2191-2196.

[32] D. Constantinescu, K. Schaber, F. Agel, M.H. Klingele, T.J.S. Schubert, J. Chem. Eng. Data 52 (2007) 1280-1285.

[33] Q. Zhou, Y. Song, Y. Yu, H. He, S. Zhang, J. Chem. Eng. Data 55 (2010) 1105-1108.

[34] A.J.L. Costa, M.R.C. Soromenho, K. Shimizu, I.M. Marrucho, J.M.S.S. Esperança, J.N.C. Lopes, L.P.N. Rebelo, J. Phys. Chem. B 116 (2012) 9186-9195.

[35] J.M. Prausnitz, R.J. Lichtnethal, E.G. Azevedo, Molecular Thermodynamic of Fluid Phase Equilibria, 3rd edition, Prentice Hall, Inc, New Jersey, 1999

[36] J. Wang, D. Zheng, L. Fan, L. Dong, J. Chem. Eng. Data 55 (2010) 2128-2132.

[37] A.E. Andreatta, M. Francisco, E. Rodil, A. Soto, A. Arce, Fluid Phase Equilib. 300 (2011) 162-171.

[38] N. Calvar, B. González, E. Go'mez, A.N. Domi'nguez, J. Chem. Eng. Data 54 (2009) 1004-1008.

[39] V.H. Alvarez, S. Mattedi, M. Aznar, J. Chem. Thermodyn. 43 (2011) 895-900.

[40] R. Chen, L. Zhong, C. Xu, J. Chem. Eng. Data 57 (2012) 155-165.
[41] A. Arce, J. Martínez-Ageitos, A. Soto, Fluid Phase Equilib. 122 (1996) 117-129.

[42] N. Calvar, B. González, E. Gómez, Á. Domínguez, J. Chem. Eng. Data 51 (2006) $2178-2181$

[43] N. Calvar, B. González, E. Gómez, A. Domínguez, Fluid Phase Equilib. 259 (2007) $51-56$.

[44] P.J. Carvalho, I. Khan, A. Morais, J.F.O. Granjo, N.M.C. Oliveira, L.M.N.B.F. Santos, J.A.P. Coutinho, Fluid Phase Equilib. 354 (2013) 156-165.

[45] L. Ninni, A.J.A. Meirelles, Biotechnol. Progr. 17 (2001) 703-711.

[46] S.P. Pinho, J. Chem. Eng. Data 53 (2008) 180-184.

[47] S. Lindenbaum, G.E. Boyd, J. Phys. Chem. 68 (1964) 911-917.

[48] A. Klamt, COSMO-RS from Quantum Chemistry to Fluid Phase Thermodynamics and Drug Design, Elsevier, Amsterdam, The Netherlands, 2005.

[49] A. Klamt, Wires Comput. Mol. Sci. 1 (2011) 699-709.

[50] G. Vakili-Nezhaad, M. Vatani, M. Asghari, Chem. Eng. Commun. 200 (2013) $1102-1120$.

[51] S. Martinho, J.M.M. Araújo, L.P.N. Rebelo, A.B. Pereiro, I.M. Marrucho, J. Chem. Thermodyn. 64 (2013) 71-79.

[52] M.G. Freire, L.M.N.B.F. Santos, I.M. Marrucho, J.A.P. Coutinho, Fluid Phase Equilib. 255 (2007) 167-178.

[53] M.G. Freire, S.P.M. Ventura, L.M.N.B.F. Santos, I.M. Marrucho, J.A.P. Coutinho, Fluid Phase Equilib. 268 (2008) 74-84

[54] M. Diedenhofen, F. Eckert, A. Klamt, J. Chem. Eng. Data 48 (2003) 475-479.

[55] K.N. Marsh, J.A. Boxall, R. Lichtenthaler, Fluid Phase Equilib. 219 (2004) 93-98

[56] U. Domanska, A. Pobudkowska, F. Eckert, Green Chem. 8 (2006) 268-276.

[57] P. Reddy, M. Aslam Siddiqi, B. Atakan, M. Diedenhofen, D. Ramjugernath, J. Chem. Thermodyn. 58 (2013) 322-329.

[58] A.R. Ferreira, M.G. Freire, J.C. Ribeiro, F.M. Lopes, J.G. Crespo, J.A.P. Coutinho Ind. Eng. Chem. Res. 50 (2011) 5279-5294.

[59] K.A. Kurnia, J.A.P. Coutinho, Ind. Eng. Chem. Res. 52 (2013) 13862-13874

[60] R. Lü, H. Tangbo, Z. Cao, J. Nat Gas Chem. 16 (2007) 70-77.

[61] E.A. Turner, C.C. Pye, R.D. Singer, J. Phys. Chem. A 107 (2003) 2277-2288.

[62] R. Anantharaj, T. Banerjee, Fluid Phase Equilib. 293 (2010) 22-31.

[63] S. Aparicio, R. Alcalde, M. Atilhan, J. Phys. Chem. B 114 (2010) 5795-5809.

[64] N. Muhammad, M.I. Hossain, Z. Man, M. El-Harbawi, M.A. Bustam, Y.A. Noaman, N.B.M. Alitheen, M.K. Ng, G. Hefter, C.Y. Yin, J. Chem. Eng. Data 57 (2012) 2191-2196.

[65] D.G. Archer, J. Phys. Chem. Ref. Data 28 (1999) 1-17.

[66] J.A. Rard, S.L. Clegg, J. Chem. Eng. Data 42 (1997) 819-849.

[67] a.d.o.U.o.K.a.F.K.G. TURBOMOLE V6.1 2009, 1989-2007, 25 GmbH, since 2007; available from http://www.turbomole.com, in press.

[68] A.K.F. Eckert, COSMOtherm Version C2.1 Release 01.08, COSMOlogic GmbH \& Co. KG, Leverkusen, Germany, 2006, in press.

[69] R. Fleming, J. Chem. Soc. 0 (1961) 3100-3102.

[70] J.B. Macaskill, M.S. Mohan, R.G. Bates, Anal. Chem. 49 (1977) 209-212.

[71] L.M.N.B.F. Santos, J.N. Canongia Lopes, J.A.P. Coutinho, J.M.S.S. Esperança, L.R Gomes, I.M. Marrucho, L.P.N. Rebelo, J. Am. Chem. Soc. 129 (2006) 284-285. 